\title{
SENTIDO DE LAS UNIVERSIDADES CON IDEARIO EN UNA SOCIEDAD PLURALISTA*
}

\author{
Manfred Svensson \\ Universidad de los Andes \\ Joaquin García-Huidobro
}

Universidad de los Andes

\begin{abstract}
RESUMEN: Este artículo presenta una defensa de las universidades con idearios explícitos. La argumentación se realiza desde un plano histórico, político y epistemológico, preguntando en cada caso por los modos en que tales idearios pueden tener sentido en contextos pluralistas como el contemporáneo.

Palabras Clave: universidad, confesionalidad, pluralismo.

RECIBIDO: junio 2015; ACEPTADO: septiembre 2015.
\end{abstract}

\section{CONFESSIONAL UNIVERSITIES IN A PLURALIST SOCIETY}

ABSTRACT: This article is a defense of confessional universities. The argument presented on their behalf has a historical, a political, and an epistemological dimension. On each of these fronts the authors show how these institutions (not only religious, but all universities with strong explicit identities) make sense in a pluralist context as the contemporary.

KEYwORDs: universities, confessionalism, pluralism.

ReCEIVED: June 2015; ACCEPTED: September 2015.

Manfred Svensson. Doctor en filosofía por la Universidad de Múnich. Director del magíster en filosofía, Universidad de los Andes. Email: msvensson@uandes.cl.

JoAquín García-Huidobro. Doctor en filosofía por la Universidad de Navarra. Director de estudios del Instituto de Filosofía de la Universidad de los Andes. Email: jgh@uandes.cl.

* Los autores agradecen los comentarios críticos de los evaluadores anónimos de Estudios Públicos. 


\section{INTRODUCCIÓN}

$\mathbf{P}$ ocos filósofos alemanes del siglo XX escribieron con tal frecuencia sobre la universidad como Karl Jaspers. Opacados tal vez por el célebre discurso rectoral de Heidegger, sus escritos nos muestran a Jaspers lidiando con el destino de la educación superior alemana en variadas etapas: su Idea de la universidad fue sustantivamente modificada en 1923, 1946 y 1961. El mayor desafío era, naturalmente, pensar en la reconstrucción de la universidad en la postguerra. ¿Cómo construir una universidad que no fuese una mera vuelta a 1932, que no fuese por tanto potencial presa fácil en situaciones críticas? Podría formularse una de las intuiciones de Jaspers al respecto señalando que percibió la centralidad del vivir en tensión: "No comprendo nada, pero dado que esto es algo que hay que comprender, voy a acabar haciéndolo"; tal era la disposición "tensa" con que caracterizaba al alumno apto para la vida universitaria. Pero se trataba también de preservar una serie de tensiones internas de la universidad. La tensión, por ejemplo, entre las innumerables tareas individuales de la universidad y su carácter de totalidad, entre la tarea científica y el comprenderse como existente para el pueblo y la humanidad. Las "tensiones irresueltas" de cada disciplina pueblan el cuadro pintado por Jaspers, incluyendo de modo prominente las tensiones entre filosofía y teología, las tensiones entre las confesiones, las tensiones entre el derecho positivo de cada Estado y las ideas de derecho natural y de gentes a las que una Facultad de Derecho también conduce. $^{1}$

Muchas de estas tensiones son, por supuesto, también chilenas, y nuestros propios pensadores han sabido también mirar la universidad con esos ojos. ${ }^{2}$ Pero en algunos puntos el escenario es distinto entre nosotros. Algunas de las tensiones que para Jaspers eran internas a toda universidad revitalizada son, en el contexto local, tensiones entre distintas universidades. Donde Jaspers piensa en facultades de derecho internamente tensionadas por el positivismo y el iusnaturalismo, tales

${ }^{1}$ Véase, en particular, la conferencia "El viviente espíritu de la universidad", en Karl Jaspers, Balance y perspectiva. Discursos y ensayos (Madrid: Revista de Occidente, 1953), 113-135.

2 Piénsese, por ejemplo, en la tensión entre la "idea relativa" y la "idea absoluta" de universidad en Jorge Millas, Idea y defensa de la universidad (Santiago: Ediciones Universidad Diego Portales, 2012). 
tradiciones tienden entre nosotros a desplegarse en universidades distintas. Ahí donde Jaspers es capaz de imaginar la existencia de distintas confesiones religiosas como algo que tensiona a una facultad de teología - una tensión que hoy en algunas universidades europeas adopta la forma de más de una facultad de teología en la misma universidad-, entre nosotros la confesionalidad más bien nos permite contrastar unas universidades con otras. En tales diferencias puede haber mucho de simple contingencia histórica: el pacto social alemán y el chileno han sido distintos; ninguno debe ser necesariamente tenido por modelo, por mucho que tengamos que aprender de lo ajeno. Pero la cuestión decisiva no es si acaso hay razones de facto que expliquen las diferencias, sino si acaso hay razones de fondo para esperar que siga siendo fecundo un modelo como el nuestro, que se puede caracterizar por la tensión entre distintos tipos de universidades.

En el debate actual sobre la educación en Chile no es inusual la tendencia a considerar las universidades con ideario como una anomalía. Son centros académicos que no responden a un específico modelo de laicidad, y que a lo más deberían ser tolerados, quizá como ejemplos de formas deficientes del quehacer universitario, o tal vez porque algunos pueden exhibir credenciales que los hacen aún imprescindibles. Pero en ningún caso podrían constituir un tipo ejemplar, capaz de presentarse en igualdad de condiciones con las restantes universidades. Uno de los argumentos que se esgrime para negarles su carácter genuinamente universitario está dado por el hecho de que sus profesores no gozarían de la misma libertad que tienen sus colegas estatales a la hora de presentar ideas o desarrollar conductas que sean opuestas al propio ideario. Se trata de una objeción importante, porque en el fondo afecta la credibilidad misma de estas instituciones de educación superior y su capacidad para participar como interlocutoras en el debate público.

Algunas universidades con ideario han respondido a esta objeción relativizando el papel del ideario en el quehacer universitario. Éste sería simplemente un ideal de la universidad entera, pero un ideal que apenas desciende a situaciones particulares. En suma, se trata de decir al resto del sistema universitario: "No se preocupen por mi nombre o por la orientación doctrinal que se señala en la página web, porque en los hechos elegimos a nuestros académicos sólo sobre la base de su currículum científico y, mientras cumplan con la Constitución y la leyes de la República, no nos preocupa lo que ellos digan o hagan”. En otros casos 
se afirma el ideario, pero en términos puramente defensivos, como si se compartiera las dudas respecto de cuán defendible resulta esta posición en el contexto contemporáneo.

En las páginas que siguen intentaremos una aproximación distinta a este problema. Si bien nuestro interés aquí no es descender a la consideración de casos particulares, sí procuraremos defender la razonabilidad de que estos idearios impriman su sello de modo sustantivo en las instituciones en que se encarnan.

Antes puede ser pertinente una palabra sobre la caracterización general de dichos "idearios" y sobre lo que se sugiere al defender que éstos puedan reflejarse en el conjunto del actuar de una institución. Entendemos por universidades con ideario aquellas que, en su misión institucional, hacen explícita una determinada cosmovisión y que constituye la base común desde la que realizan su quehacer universitario los académicos que trabajan en ella. Cabe notar que numerosas instituciones de nuestro país se presentan como portadoras de un ideario semejante. La Pontificia Universidad Católica declara aspirar "a lograr la excelencia en la creación y transferencia del conocimiento y en la formación de personas, inspirada en una concepción católica y siempre al servicio de la Iglesia y la sociedad"; 3 la Universidad Adventista de Chile "promueve una educación integral fundamentada en principios y valores cristianos extraídos de las Sagradas Escrituras, para la formación de profesionales competentes, al servicio de Dios y la humanidad"; 4 la ARCIS declara otorgar "sólida formación académica y compromiso social que contribuyan al desarrollo de una sociedad más justa e inclusiva". ${ }^{5}$ Esto puede ser contrastado con algunas universidades cuyos distintivos idearios quedan algo escondidos por la generalidad de la misión que se declara. ${ }^{6}$ Puede, también, ser contrastado con universida-

3 "Misión y visión", http://acreditacion.uc.cl/index.php?option=com_content\& view $=$ article \&id=23\&Itemid=83/ (accesado el 22 de junio de 2015).

4 “Misión y visión", http://www.unach.cl/index.php/universidad/mision-yvision/ (accesado el 22 de junio de 2015).

5 "Misión y visión", http://uarcis.cl/index.php/somos-uarcis/mision-y-vision/ (accesado el 22 de junio de 2015).

${ }^{6}$ Considérese, por ejemplo, la descripción de la misión de la Universidad de la República como "laica, pluralista y tolerante". "Visión y misión", http://www. ularepublica.cl/index.php/universidad/vision-mision.html (accesado el 8 de octubre de 2015). 
des que, si bien poseen un ideario, se han desarrollado más allá de éste: si Andrés Bello declaraba en el discurso inaugural de la Universidad de Chile que "el programa de la Universidad es enteramente chileno", se puede estar agradecido de que tal ideario no haya guiado cada paso del actuar institucional. Pero lo que aquí nos interesan son aquellos casos en que el ideario es consciente y explícitamente afirmado como aquello que guía una institución. Y tales idearios pueden en esos casos modelarla de diversos modos: desde las políticas de contratación, pasando por la estructura curricular o las áreas privilegiadas de investigación. Es a estos casos que dirigimos la mirada a continuación. Lo haremos atendiendo al problema desde tres ángulos distintos: uno histórico, uno político y uno filosófico. Tras esto, presentaremos algunas consideraciones finales.

\section{PLURALISMO Y CONFESIONALIDAD EN LA HISTORIA DE LA UNIVERSIDAD}

En este trabajo, el objeto privilegiado de discusión serán las universidades de inspiración cristiana. Como lo indica nuestro título, muchas de las reflexiones aquí contenidas se pueden extrapolar a otras universidades con ideario específico y explícito. Hablar de "ideario" permite no sólo señalar que mucho de lo que aquí dicho puede aplicarse a universidades de inspiración opuesta, sino que permite evitar las confusiones derivadas del hecho de que con el término "confesional" se designa ocasionalmente en nuestro medio a las que son de propiedad eclesiástica, y no a las que simplemente se inspiran o fundan en un ideario de tal naturaleza. Por varias razones tiene sentido concentrarse de modo individual en las universidades de inspiración cristiana (en el caso de nuestro país, básicamente las universidades católicas, aunque la reflexión que sigue no muestre dicha especificidad). Entre los motivos para concentrarse en estas instituciones puede nombrarse el hecho de que son, a fin de cuentas, las más abiertamente cuestionadas en el debate actual. Eso puede deberse a una fobia antirreligiosa, o puede deberse a que ellas se ven envueltas con facilidad en las discusiones morales ("valóricas", como se ha dado en llamarlas), que son debates que no siempre se conducen en el tono que identificamos con la vida universitaria. Pero puede también deberse a un hecho menos circunstancial: el 
ideario de estas universidades muchas veces es explícito del modo en que no lo suelen ser todos los idearios. Si esto es así, constituyen uno de los casos por excelencia de las universidades con ideario, y ciertamente de los conflictos que pueden surgir en torno a ellas.

En términos de historia de las universidades, no puede caber duda alguna de la veracidad de la afirmación anterior: idearios con expresión universitaria hay muchos, pero ninguno con un historial como el del cristianismo. Desde antiguo a tales universidades las ha animado la convicción de que existe una compatibilidad entre fe y razón. Esa convicción ha dado origen a un diálogo muy fructífero a lo largo de la historia. Éste no ha carecido de tensiones, pues afirmar la compatibilidad entre fe y razón deja aún abiertas muchas preguntas respecto del modo específico en que se articularían. Pero los distintos modos de concebir la relación comparten la convicción, heredada del judaísmo, de que el universo es fruto de una inteligencia creadora y que, por tanto, presenta un rostro legible. Esta concepción ha sido históricamente decisiva para el surgimiento no sólo de las tradiciones filosóficas que se desarrollaron junto con el surgimiento de la universidad, sino también de la ciencia moderna, que - si bien surge bajo influencias también muy distintas del cristianismo- no podía surgir en contextos panteístas o politeístas, donde lo que acaece no puede ser explicado por un orden racional, sino, por ejemplo, por la voluntad de un dios u otro. ${ }^{7}$

Pocas veces en su historia posterior la universidad tuvo una influencia tan decisiva en la configuración de la cultura como la que mantuvo en el siglo XIII en Europa, cuando se debatió la compatibilidad entre la ciencia, representada por la obra de Aristóteles, que recientemente había sido traducida al latín, y la fe cristiana. La rutinaria narración de ese hecho puede habérnoslo vuelto demasiado familiar. Su radicalidad puede hacerse visible comparándolo con la moderna revolución científica, pero imaginando que ésta hubiese tenido de golpe en lugar de constituir un desarrollo gradual: Europa recibió de modo repentino una visión de mundo completa, que elevaba de modo significativo sus patrones de cientificidad, y — no sin controversia- supo absorberla mediante el trabajo de sus universidades. A diferencia de lo que sucedió en el mundo islámico — diferencia dada no tanto a nivel individual, pero

${ }^{7}$ Así Stanley Jaki, "La función de la fe en la física", en su libro Ciencia, fe, cultura (Madrid: Palabra, 1990), 117-138, esp. 127; o Stanley Jaki, “Aspectos teológicos de la ciencia creativa”, también en Ciencia, fe cultura, 139-143; 152-155. 
sí, que es lo que aquí decisivo, a nivel institucional-, la respuesta positiva a esta cuestión marcó la evolución de la cultura europea. Esta concepción, mantenida por la universidad medieval, que compatibiliza fe y razón, no puede ser entendida como el simple estado embrionario de la institución universitaria, sino que se prolongó por siglos y marcó momentos de particular esplendor en la vida de la institución universitaria. Un caso significativo se halla en el siglo XVI español, con el papel de la Universidad de Salamanca en la clarificación de las polémicas de Indias, que llevó a afirmar el carácter de personas libres de los aborígenes americanos, otorgando un fundamento racional a ciertas verdades que bien podían conocerse por la fe. Se trata de una de las discusiones más importantes de la historia de Occidente, cuya solución se facilitó por la existencia de esta convicción de la compatibilidad de fe y razón, y por la pluralidad de fuentes a la que tal disposición naturalmente abría. No se trataba de una solución intrascendente, porque significó un claro desafío a los intereses inmediatos de los poderes políticos y económicos vigentes en ese tiempo, como se puede ver en la resistencia de los encomenderos y de diversas autoridades americanas a las tesis de Las Casas y otros a favor de los indios. ${ }^{8}$

La encrucijada recién descrita permite considerar una forma en que las universidades con ideario permitieron poner límite al trato deshumanizante con el "otro". Pero de modo paralelo, cabe considerar el singular desarrollo que por la misma época implicó el tener universidades con idearios contrapuestos. El periodo de la post Reforma nos ofrece, en efecto, universidades que de manera distinta, y en recíproca polémica, hacen suya la herencia medieval. Lo característico de este periodo son las confesiones en conflicto, un conflicto cuya productividad es crecientemente reconocida: el protestantismo trajo desde el primer momento consigo tanto la fundación de algunas universidades nuevas (Marburgo ya en 1527, una década tras el inicio de la Reforma) como la revitalización de otras; en respuesta - pero también como parte del propio impulso reformista católico - surge la robusta red de universidades jesuitas. Con el mismo ímpetu que llevaba a tener la división confesional por cuestión de vida o muerte, a ambos lados de la división se compartía una tradición científica y literaria de siglos, una tradición

${ }^{8}$ Ver David Brading, Orbe indiano. De la monarquía católica a la república criolla, 1492-1867 (México: Fondo de Cultura Económica, 1991), 75-90. 
cuyo seno escolástico fue capaz de acoger al mismo tiempo el influjo humanista y el temprano desarrollo de la ciencia moderna. A diferencia de la aún relativamente homogénea universidad medieval, aquí tenemos una mezcla de confesionalidad y polémica que en algunos sentidos resulta muy cercana a nuestra situación actual. También entre nosotros la universidad confesional es parte de un mundo de confesionalidad dividida, aunque nos separe de dicho periodo el entonces compartido sustrato supraconfesional, hoy difícilmente imaginable. ${ }^{9}$

El gradual ocaso de la universidad confesional de la post Reforma traería finalmente consigo un último tipo de universidad con ideario. ${ }^{10}$ En efecto, el siglo XIX trae consigo la fundación de una serie de universidades confesionales, tanto en el mundo católico como en el protestante, pero consiste en un escenario distinto del recién discutido: se trata de respuestas conscientes a un mundo ya modernizado y secularizado, y de esa manera, también, de una integración sui generis a dicho mundo. "No es un convento, no es un seminario, sino un lugar en el que hombres del mundo se preparan para el mundo", escribía Newman a propósito de una de esas fundaciones. ${ }^{11}$ Este contraste entre las universidades confesionales tradicionales y las que nacen en un contexto decimonónico desde luego no es total. No sólo hay continuidad, sino un esfuerzo de recuperación y ressourcement. Pero hay conciencia de fundarse en un contexto pluralista, contexto que no se rechaza. Abraham Kuyper, primer rector y fundador de la Universidad Libre de Ámsterdam, habla en el discurso inaugural del enfrentamiento entre "confesiones diametralmente opuestas" al que la universidad contribuiría. ${ }^{12}$ Ya no estamos

9 De entre una amplia literatura sobre este fenómeno puede verse Joseph Freedman, Philosophy and the Arts in Central Europe, 1500-1700: Teaching and Texts at Schools and Universities (Aldershot: Ashgate, 1999).

${ }^{10}$ Para la transformación de la vieja universidad puritana véase George Marsden, The Soul of the American University. From Protestant Establishment to Established Nonbelief (Oxford: Oxford University Press, 1994); para la reformulación de tal proyecto en contexto pluralista véase del mismo Marsden, The Outrageous Idea of Christian Scholarship (Oxford: Oxford University Press, 1998).

11 John Henry Newman, The Idea of a University: Defined and Illustrated (Washington: Regnery Publishing, Washington, 1999), 210.

12 El discurso inaugural puede consultarse en Abraham Kuyper, "Soberanía de las esferas", Estudios Evangélicos junio 2013. Para más detalle del contexto y sus paralelos en la discusión holandesa sobre la configuración del sistema escolar, véase James Bratt, Abraham Kuyper. Modern Calvinist, Christian Democrat (Grand Rapids, MI: Eerdmans, 2013). 
ante el conflicto entre quienes comparten una tradición intelectual supraconfesional. Este "confesionalismo de segunda generación", si cabe llamarlo así, destaca por el modo en que su pretensión confesional carece de pretensiones hegemónicas, se integra a sí mismo en un ambiente que acepta como plural. Pero en el mismo discurso Kuyper muestra que se trata también de un proyecto para una situación post positivista: las posiciones rivales encarnadas en instituciones de educación superior, escribe, requieren de una amplia libertad (respecto de autoridades tanto eclesiásticas como políticas), pero una libertad que no se entiende a sí misma como una emancipación del principio animante de la institución. Salta a la vista el contraste con la posición que pocas décadas más tarde formularía Weber al sugerir que "apenas el hombre de ciencia introduce el juicio de valor, la comprensión de su materia cesa". ${ }^{13}$

Lo anterior es de relevancia inmediata para la discusión actual por tratarse del espíritu que anima al mayor número de las universidades con ideario sobre las que hoy se discute: éstas no son simples resabios medievales (aunque en algunos sentidos puedan orgullosamente pretender serlo), sino expresión de una confesionalidad que se afirma como integrada en una modernidad plural. Pero en cuestión está no sólo el carácter de facto plural de dicho mundo, sino qué modos de pensar sobre este pluralismo permiten mantener abierto el sistema por principio (punto sobre el que volveremos más adelante).

\section{LA UNIVERSIDAD CON IDEARIO EXPLÍCITO EN LA SOCIEDAD PLURAL}

Lo anterior nos lleva de inmediato al modo en que la universidad con ideario se inserta en la sociedad plural contemporánea. Nos conduce así desde la justificación histórica a la justificación política. Pero eso implica que, antes de hablar sobre pluralismo y tolerancia, se hable sobre el poder. Cabe aquí notar la importancia que tiene la comprensión de las universidades como foco de poder. En ellas, después de todo, se forma el capital cultural de un país. La universidad no es la forma más visible del poder, pero por lo mismo merece tanta mayor atención. Comprendiendo el lugar que desempeña el poder en ellas, se entiende

${ }^{13}$ Max Weber, "Wissenschaft als Beruf", en Schriften 1894-1922, editado por Dirk Kaesler (Stuttgart: Alfred Kröner, 2002), 498. 
también la importancia de que este poder se encuentre diversificado, en concordancia con la idea liberal de división de los poderes. ${ }^{14}$ Por lo pronto, quien considere el sistema universitario chileno puede constatar aquí un escenario no del todo lamentable: el poder universitario se encuentra dividido entre el Estado y los privados, y se encuentra asimismo dividido entre una amplia variedad de privados, también por lo que a su ideario se refiere. Pocos dudarán de que hay situaciones que merecen corrección; pero la cuestión es si acaso las correcciones que se considera se dirigen o no a fortalecer la división de este tipo de poder o a su mayor concentración.

Pero de esta óptica no sólo deben ser convencidos los escépticos respecto de las universidades con ideario; también tienen que ser convencidos quienes hablan desde perspectivas confesionales con frecuencia reticentes a ensuciar su discurso con una consideración del poder. Su cautela es explicable: la mención del poder puede parecer propia de un discurso que busca desenmascarar toda ciencia como nada más que expresión de poder. Siguiendo tal ruta, la defensa de los idearios que animan a algunas universidades bien podría acabar en un simple juego de identificación entre verdad y poder, ya sea sugiriendo que toda universidad puede ser justificada por tal identidad, ya sea desenmascarándolas a todas como representantes de diversos poderes. Pero no tiene por qué ser tal cinismo lo que esté en juego. Le Goff ha llamado la atención sobre la centralidad del hecho de que las universidades surgieran de la mano de la revitalización de las ciudades. ${ }^{15}$ Desde su surgimiento, la universidad se encamina a volverse una fuerza de relevancia comparable al imperio y el sacerdocio. Nadie que se familiarice con ese hecho podrá considerar el poder como un foco irrelevante para la discusión sobre las universidades.

Más usual, pero compatible con esta aproximación a nuestro tópico desde la división del poder, es la aproximación desde el pluralismo. Esta última, sin embargo, es más compleja por la variedad de comprensiones del pluralismo que circulan, en contraste con la algo más

14 Juan Manuel Garrido, Hugo Herrera y Manfred Svensson, La excepción universitaria (Santiago: Ediciones Universidad Diego Portales, 2012), 72-3. Este punto ha sido luego desarrollado por Hugo Herrera en diversos contextos.

15 Jacques LeGoff, Los intelectuales en la Edad Media (Barcelona: Gedisa, 1993), 67-80. 
sencilla lógica de división del poder. Al abordar el pluralismo como eje de la discusión, se nos abren de partida dos tipos de pregunta: preguntas sobre la contribución de las universidades con ideario al pluralismo, y preguntas sobre el pluralismo interno que debiera (o no) caracterizarlas. Cada una de estas cuestiones puede, a su vez, ser abordada tanto en relación con el papel social de la universidad como en relación con la adquisición de conocimiento. Desde luego no todo lo de ahí derivado será cubierto aquí. ${ }^{16}$

Sí parece ineludible tocar el problema del pluralismo interno de las universidades. El pluralismo es una nota que se predica del sistema universitario general, de una forma semejante a cómo se predica de las sociedades contemporáneas. No se predica, en cambio, de las personas individuales. Ninguna persona es, en sentido estricto, pluralista. Puede, por cierto, respetar la pluralidad, tener lo que habitualmente se llama una "actitud pluralista", pero ser ella misma pluralista, en el sentido de que convivan en su mente visiones contrarias de la realidad, es un imposible, salvo como estado pasajero del que precisamente la educación universitaria busca sacarnos. Pero entre el pluralismo que exigimos al sistema universitario en general y la imposibilidad del mismo en individuos particulares se encuentran, por supuesto, las universidades individualmente consideradas. ¿En qué medida a todas y cada una de ellas ha de exigírseles pluralismo?

Cabe iluminar la cuestión a partir de otro campo de la sociedad: a nadie se le ocurriría, en sentido estricto, exigir que un partido político sea pluralista, a no ser en el sentido obvio de que no sea totalitario ni pretenda destruir al resto de los participantes del juego político. Así, un partido socialista no puede admitir en su seno ideas conservadoras o propuestas económicas de la Escuela de Chicago sin destruirse a sí mismo. Esto no constituye ningún problema para la democracia, siempre que en el mismo país haya otros partidos, que tengan posturas diferentes, de modo que el conjunto sí resulte pluralista. El ejemplo apunta solo a una analogía y, obviamente, no se puede trasladar de modo íntegro al mundo universitario. En primer lugar, porque la universidad es el tipo de institución en la que no deben reinar actitudes partidistas. En segundo lugar, a diferencia de los partidos políticos, sí cabe que haya

${ }^{16}$ Para esta división del problema y su desarrollo véase Garrido, Herrera y Svensson, La excepción, 80-93. 
una universidad donde efectivamente convivan académicos de talante filosófico muy distinto e incluso contrapuesto. En tercer lugar, porque aunque el partido puede producir conocimiento, por ejemplo mediante instituciones de investigación vinculadas, lo hace con un control sobre dicho "producto" que es distinto de la novedad - "sorprendente", podríamos decir - de la investigación en ciencias y humanidades. Sin embargo, la comparación entre el sistema universitario y el sistema político ayuda a entender cómo la existencia de universidades con ideario permite que el diálogo social experimente una mayor riqueza, que puede ir en beneficio del conjunto social. Dicho con otras palabras, una sociedad en la que no existen universidades con ideario tendrá una discusión pública más pobre que esa misma sociedad en un escenario donde puede contar con ellas. Como dice MacIntyre:

Una tradición madura justo en la medida en que sus seguidores se enfrentan y encuentran un modo racional para superar esos encuentros con posturas radicalmente diferentes e incompatibles que plantean problemas de inconmensurabilidad y de no-traducibilidad. ${ }^{17}$

Reconocer la importancia de esa diversidad no implica, por cierto, compartir todos y cada uno de los proyectos universitarios existentes, cosa por lo demás imposible, sino tratarlos como algo valioso para otros (siguiendo la distinción que entre nosotros ha sostenido M. E. Orellana Benado entre vivir y tratar una realidad como valor). ${ }^{18}$

Ahora bien, lo anterior es aceptado con facilidad cuando se trata sólo de posiciones individuales: no es una experiencia en lo más mínimo extraña que tanto profesores como estudiantes manifiesten respeto por aquello que sus pares valoran, sin tener por ello que valorarlo ellos mismos. Pero la aplicación de esta idea a las universidades con ideario implica un desafío algo mayor, por cuanto implica que se aprenda a ver las instituciones en cuanto tales como sujetos cuyas valoraciones pudiesen ser enfocadas así. En lugar de eso, hay una tendencia a considerar las universidades a la luz del modelo del Estado: tal como éste, las

${ }^{17}$ Alasdair MacIntyre, Justicia y racionalidad. Conceptos y contextos (Barcelona: Eiunsa, 1994).

18 Miguel Orellana Benado, Pluralismo: una ética del siglo XXI (Santiago: Editorial Universidad de Santiago, 1994). 
universidades tendrían que ser neutrales, en contraste con los individuos a los que se pide tolerancia en lugar de neutralidad. ${ }^{19}$ Pero las universidades, como los restantes cuerpos intermedios, difieren del Estado, no sólo en términos cuantitativos, sino también cualitativos: como otros cuerpos sociales, ellas son intermedias no sólo en cuanto a su tamaño, sino en el modo de ligarse a contenidos específicos o visiones de la realidad. Del Estado solemos pedir que no favorezca a ninguna visión de la realidad por sobre otras, mientras que del individuo singular esperamos que siempre esté guiado por alguna convicción en particular; de las universidades, como de muchas otras sociedades intermedias, no solemos esperar ninguno de estos dos extremos, y se encuentran así en una situación propia en lo que a la tolerancia se refiere. ${ }^{20}$ Quien haya comprendido la dificultad para zanjar a priori los problemas de tolerancia e intolerancia cuando se trata del Estado y del individuo verá con facilidad cuánto más difícil puede ser en el caso del complejo espacio intermedio que ocupan instituciones como las universidades. Una aproximación prudencial, en efecto, puede ser más apropiada para resolver este tipo de conflictos, pero ella implica que el Estado resista la tentación de imponer al resto de los cuerpos sociales la imparcialidad que se le pide a él.

\section{TRADICIÓN EN COMÚN: NECESIDAD Y UTILIDAD}

Junto con una visión de la historia de la universidad y de la naturaleza del pluralismo, la defensa de las universidades con ideario tiende a ir de la mano con ciertas concepciones epistémicas. En el caso de las universidades de inspiración cristiana, tal vínculo salta a la vista: la universidad nace en un medio que se vería prontamente puesto en tensión por la recepción de Aristóteles, pero que antes es guiado por la divisa agustiniana de creer para comprender. Nace, en otras palabras, en un contexto en el que es común la aceptación de ciertos prerrequisitos in-

${ }^{19}$ A modo de ejemplo de tal requisito puede verse José Feliz Lozano Aguilar, Pedro Jesús Pérez Zafrilla y Elsa González Esteban, "The Limits of Tolerance in Public Universities", Politics in Central Europe 4, n. ${ }^{\circ} 2$ (2008): 15.

${ }^{20}$ Para dicha posición véase Manfred Svensson, "Hacia una concepción robusta de mera tolerancia," en Una disposición pasajera. Sexto concurso de ensayo en humanidades contemporáneas (Santiago: Ediciones Universidad Diego Portales, 2013), $72-77$. 
telectuales y morales para la adquisición de conocimiento. Pero ese tipo de concepción epistémica, aunque en un sentido sea "tradicional", en otro sentido es objeto de renovada consideración en el contexto filosófico contemporáneo: el lugar de la tradición o la preconcepción (o incluso del "prejuicio", si pensamos en Gadamer ${ }^{21}$ en el proceso de comprensión es uno que hoy menos pensadores consideran en términos puramente negativos. Una consideración de ese aspecto de la filosofía contemporánea puede naturalmente acabar invirtiendo el peso de la prueba: la cuestión no es si acaso es lícito que haya universidades con idearios específicos, sino si acaso es posible la universidad sin ideario. Con todo, este escenario actual puede ser tan promisorio como riesgoso: puede implicar que se acabe defendiendo la universidad con ideario como una ideología más. A continuación intentaremos explicar por qué la evasión de ese riesgo, ciertamente indispensable, debe recorrer una ruta distinta de la simple vuelta a las condiciones de neutralidad moderna.

Cabe partir notando que quien evalúe el escenario contemporáneo con esta inquietud en mente se encuentra con señales opuestas. Por una parte, es creciente el número de instituciones que busca dar cuenta de la posesión de un ideario. No tiene por qué tratarse de un ideario "robusto", como el marxismo o el cristianismo; pero las declaraciones axiológicas, que muestren que la institución posee un tipo u otro de "conciencia" (social, ecológica, etcétera), son un fenómeno cotidiano. Por otra parte, sin embargo, sigue poseyendo cierta efectividad retórica la pretensión de neutralidad de una casa de estudios. Son, así, también muchas las universidades que no adhieren explícitamente a ninguna tradición. Eso no significa que sus académicos no adscriban siempre a una tradición determinada o que en ellas no haya tradiciones que permanecen implícitas. Uno de los elementos que enturbian la discusión es, probablemente, el hecho de que una de las tradiciones en disputa, la ilustrada, se presenta a sí misma como si estuviera más allá de todo prejuicio y tradición, con la consiguiente situación de superioridad respecto del resto de las tradiciones que dicha pretensión le otorga. Pero esa actitud, como señaló Gadamer hace muchos años, bien podría no ser más que otro prejuicio, el de la libertad respecto de todos los prejuicios.

${ }^{21}$ Sobre el prejuicio ilustrado contra los prejuicios: Hans Georg Gadamer, Wahrheit und Methode. Grundzüge einer philosophischen Hermeneutik, $6^{\mathrm{a}}$ ed. (Tubinga: J. C. B. Mohr, 1990), 275. 
Aunque las tomas de posición sean así omnipresentes, su carácter varía de disciplina en disciplina. Pero que en cada una de ellas tienda a haber tradiciones con carácter normativo salta a la vista. La corriente ampliamente mayoritaria en la actualidad lleva a que en economía se enseñe algo muy semejante a la economía clásica, y esa idea de fondo actúa como un cierto criterio unificador de toda la enseñanza. Esta decisión no es ideológicamente neutra, por más que permanezca implícita y sea ampliamente compartida. Y si en algunos lugares o épocas se ha enseñado, por el contrario, la misma disciplina echando mano de El capital de Marx o de las teorías desarrollistas que propuso la Cepal en la década de los sesenta, ello se hizo no en virtud de la neutralidad, sino en virtud de una convicción respecto de la pertinencia de dichas teorías. Otro tanto sucede en medicina: en ninguna de nuestras facultades se destinan los cursos troncales a enseñar, al mismo nivel, las prácticas de la medicina tradicional indígena y el manual de Harrison de medicina interna, o el texto que haga sus veces. Ni la norma ni la alternativa a la misma (como la homeopatía) se fundan en la neutralidad, sino que corresponden a una determinada idea de lo que debe ser la actividad médica.

Alguien podría argumentar que la observación precedente no viene al caso, pues la economía y la medicina tienen un estatuto científico, que permite afirmar en ellas la existencia de ciertas leyes que son objetivas. Un modo análogo de formular la objeción es señalar que las tomas de posición ahí presentes dependen no de un ideario, sino de la capacidad predictiva de las teorías en cuestión. En cualquiera de esas formulaciones el punto es que estaríamos en el mundo de los hechos, en contraste con el carácter valorativo de las humanidades, donde la presencia de preconcepciones se acepta más fácilmente. Sin embargo, ese argumento sólo vale cuando ya se ha asumido la distinción tajante entre el mundo de los hechos y el de los valores, que es algo que requiere ser probado y no puede darse por supuesto. En tanto que no es probada, en tanto que no se abordan las sustantivas críticas que el pasado siglo ha dejado contra ella, ${ }^{22}$ esa separación es tratada ella misma como una

${ }^{22}$ A modo de ilustración véase Hillary Putnam, The Collapse of the Fact. Value Dichotomy and Other Essays (Cambridge, MA: Harvard University Press, 1992). Pero bien cabe añadir que éste es uno de aquellos puntos subyacentes a gran parte de la controversia liberal-comunitarista que rara vez son detenidamente abordados por parte de la defensa de la tradición liberal. 
suerte de confesión de fe por quienes la esgrimen. A partir de esa neta distinción, asumida muchas veces de modo acrítico, se declara que el campo de los valores no está sujeto a una discusión racional, en paralelo con una simplificación del modo en que opera la racionalidad en un desnudo mundo de los hechos.

Pongamos de nuevo un ejemplo tomado de la medicina, aunque puede aplicarse también a la psicología y las demás ciencias de la salud. Ellas recurren constantemente a conceptos como el de "hombre sano". Pero un concepto tal está teñido de filosofía. Supongamos que, para evitarnos problemas, decimos que ese concepto lo construiremos de modo estadístico. ¿Estaremos en ese caso siendo neutrales? ¿No supone ya esa invocación a la estadística como criterio de normalidad una propuesta implícita de adaptación al sistema, que bien podría ser calificada de "conservadora" en el peor sentido de la palabra? ¿No puede ser racionalmente defendible una concepción no adaptativa de la salud mental? Veamos un ejemplo más conflictivo: supongamos que hacemos una investigación sobre los hijos que viven con un progenitor que tiene una pareja del mismo sexo. Queremos saber si en esos casos se observan trastornos especiales en esos jóvenes. ¿Vamos a incluir a la homosexualidad (o las actitudes favorables o críticas respecto de la misma) entre dichos trastornos? Sea que demos una respuesta afirmativa o negativa, ella sólo tendrá sentido en el marco de una antropología determinada e incluso de una filosofía política.

En La ciencia como vocación, texto que bien puede ser considerado como la más clásica defensa del principio de neutralidad moderno en cuanto aplicado a la vida universitaria, Max Weber concedía que hay un sentido en que esta última observación nuestra puede ser pertinente. Pues su defensa del ideal de neutralidad acaba con una defensa del deber académico de mostrar la conexión entre conclusiones o prácticas puntuales, por una parte, y visiones de mundo, por otra. Tal conexión es algo de lo que se puede hablar también desde la posición neutralista. Weber consideraba que es así como la ciencia contribuye a la honestidad intelectual: "podemos y debemos decirles [a los alumnos] que tal y cual posición práctica puede ser deducida de modo consecuente, con fidelidad a su sentido, a partir de tal visión fundamental del mundo [weltanschauungsmäßigen Grundposition]". ${ }^{23}$ En otras palabras, lo que

${ }^{23}$ Weber, "Wissenschaft als Beruf", 505. 
el profesor, y por extensión la universidad, podría hacer es simplemente mostrar a qué dioses se profana y a cuáles se venera con cada toma de posición; sin por eso decirnos a qué dioses conviene venerar. Pero es ese "politeísmo de los valores" el que aquí nos separa de él. Pues si bien la conexión entre posición práctica y toma de posición fundamental es para Weber objeto legítimo de exposición académica, la posición fundamental misma se escapa a la razón, por lo que el académico a lo sumo impulsa a sus oyentes a la decisión entre valores rivales, los que por su parte no pueden ser objeto de dilucidación racional. ${ }^{24}$

Antes de distanciarse de esa postura, conviene notar que también desde la posición que aquí defendemos cabe simpatizar con parte de lo que mueve a Weber en este importante escrito. Pues una de las cuestiones decisivas para él es aquí asegurar la distinción entre el profeta y el profesor (contra la híbrida declamación que en un momento llama Kathederprophetien). Tal como la arenga política tiene su lugar en la asamblea partidaria, pero es algo totalmente distinto del análisis científico de la política, ocurre del mismo modo con el profeta que toca de modo legítimo las cosas últimas, pero que debería captar que su lugar está en las calles, no en el aula. ${ }^{25}$ Aquí reside gran parte de la fuerza de la posición de Weber: que también el defensor de las universidades con ideario querrá verlas distinguidas de la demagogia política, sea cual sea el ideario político en cuestión, y de la resistencia del profeta al cuestionamiento, sea cual sea la divinidad de parte de la cual hable. Pero aquí reside también una de las debilidades de Weber: al profeta le dice que su lugar está fuera de la universidad, porque ahí puede ser criticado, mientras que en la universidad el catedrático cuenta con autoridad indiscutida. Se trata de una peculiar inversión de la posición kantiana según la cual el catedrático encarna la razón pública precisamente porque su discurso, aunque informado y ponderado, puede ser objeto de discusión.

Pero a lo que eso nos abre la mirada es precisamente al hecho de que las condiciones con las que aquí se busca salvaguardar la universidad como universidad no parecen ser las correctas. Lo requerido no es menos, sino más: que precisamente se afirme todo como susceptible de discusión, sin dividir la realidad en dos campos incomunicados del

${ }^{24}$ El giro decisionista de Weber puede verse ya en "Wissenschaft als Beruf", 494 y 506.

25 Ídem, 497-8. 
hecho y del valor. ¿Es posible hacer eso desde una universidad con ideario? El llamado de un Tomás de Aquino a ver como tarea del metafísico el "cuestionamiento universal respecto de la verdad" (universalis dubitatio de veritate) así parece sugerirlo. ${ }^{26}$ Pero el punto no es aquí identificar la posición de Tomás con la de la duda sistemática moderna para así volverlo digerible. Una dubitatio, como aclara Gilson, podía significar una duda, pero también puede significar una disposición algo distinta, como la de confrontar un problema, o la de abordar una dificultad para la cual se presentan posiciones rivales que parecen igualmente meritorias. ${ }^{27}$ Tal vez no duda universal; pero sí examen universal. Lo que la afirmación de Tomás así nos recuerda es que las alternativas que tenemos por delante no se reducen a una tríada de confesionalismo ingenuo, neutralidad moderna y perspectivismo postmoderno. Hay una cuarta vía, por compleja que sea su adecuada caracterización.

En cualquier caso, la defensa de la universidad con ideario no implica que cada universidad esté simplemente mostrando cómo se ve el mundo desde un lugar particular, sino que obliga también al examen de ese lugar desde el que se mira. Afirmar el lugar central de la tradición no es volverla inmune a la crítica externa ni a la crítica interna, sino adquirir conciencia de que ninguna tradición debe ser inmune a tal crítica, y que la crítica a veces se realiza mejor cuando se hace no sólo por parte de individuos sino por (y respecto de) instituciones completas formadas por un ideario. La cuestión es particularmente importante dado el hecho de que el carácter dominante de un ideario puede volverlo invisible y eximirlo así inconscientemente de la crítica. El hacer explícita, cuando las circunstancias lo piden, la tradición a la que se pertenece constituye una muestra de honestidad intelectual y, de paso, es una actitud que facilita el diálogo, porque clarifica las bases en las que se apoya cada interlocutor.

\section{LA UNIVERSIDAD CON IDEARIO COMO CAMINO DE APERTURA}

Los caminos que hemos sugerido nos recuerdan que puede haber un futuro promisorio para las universidades con ideario. Cada uno de dichos caminos implica, por cierto, un modo de relación con institucio-

${ }^{26}$ Tomás de Aquino, In Metaph., lect. III, 1.

${ }^{27}$ Véase Etiénne Gilson, Thomist Realism and the Critique of Knowledge (San Francisco: Ignatius Press, 2012). 
nes inspiradas en idearios opuestos: estos caminos implican respeto por idearios que han sido capaces de inspirar a centenarias instituciones de educación superior, implican una disposición plural de escucha y la frecuente práctica de la tolerancia, e implican también el saber de la propia tradición como una posición que abre la mirada hacia el todo, no un gueto en el cual refugiarse. Dadas tales condiciones, las universidades con ideario pueden ser estrictamente confesionales y al mismo tiempo robustos espacios de apertura.

Se presume con facilidad que aquí estaríamos ante uno de los flancos débiles de las instituciones con ideario. Calificarlas como espacios de apertura es calificarlas como espacios de libertad, y ése es uno de los puntos que sus críticos con más frecuencia suelen cuestionar. Pero a una universidad tal se adscriben intelectuales que quieren llevar a cabo una actividad científica precisamente sobre las bases de la misma; el ideario es, así, no tanto límite, sino punto de arranque. No es que, por ejemplo, por el hecho de pertenecer al claustro de la Universidad de Notre Dame o del Sacro Cuore, un profesor de derecho esté impedido de promover la tortura como método de investigación judicial. Más bien se trata de que esa persona se adscribe a esa universidad para desarrollar, junto con otros académicos que tienen el mismo propósito, una ciencia jurídica donde la dignidad del hombre sea un pilar fundamental. Por esa razón lo expresan así en el ideario institucional.

Pero al hacer mención de la apertura está claro que para la perspectiva universitaria se pone en cuestión no sólo la apertura a una cosmovisión distinta u opuesta, sino la apertura a la realidad misma, y en particular a la novedad que, dado el carácter de la investigación moderna, suele ser uno de los elementos que caracterizan a la vida científica. Dada la centralidad que posee dicha expectativa de novedad, la pregunta que recae sobre las universidades con ideario es en qué medida están en condiciones de responder a un mundo que no sólo es plural, sino uno cuyo conocimiento avanza. Resulta patente que, en un sentido, la respuesta a esa inquietud tiene que ser abordada de un modo distinto según los idearios de las respectivas instituciones. Indudablemente puede haber idearios tan estrechos que tal adaptación a la novedad resulte improbable. Aunque, por otra parte, cabe confiar algo en la dinámica misma que adquiere un ideario por encontrar expresión universitaria: la investigación tiene una vida propia que puede volver vivo lo que sin 
expresión universitaria parecía estéril. Sea esto como fuere, y dada la atención privilegiada que el presente artículo da a las universidades de tradición cristiana, cabe notar que en dicho horizonte hay un modo característico de abordar este punto: el cristianismo no sólo ha reconocido históricamente que puede existir tal avance efectivo en el conocer, sino que incluso ha llevado esto al centro de su propia autocomprensión, al considerar que la doctrina cristiana misma puede ser objeto de desarrollo. Resulta importante no confundir esto con un ideal general de progreso. Dado que el desarrollo doctrinal es entendido como explicitación — producto de la controversia, por ejemplo — de lo antes implícitamente confesado, el desarrollo aquí en cuestión va de la mano de la idea de conservación de un "depósito de la fe". Cabe notar, por cierto, que también esto puede ser en realidad un camino de destrucción de un ideario: quien renuncia a un ideario con frecuencia puede entenderse (ya genuinamente, ya como impostura) a sí mismo como un renovador del mismo, como reformista que lo transforma desde dentro, y que por tanto se ajusta al esquema recién delineado. Pero, aquí como en los restantes escenarios, el abuso no quita el uso: existe la transformación desde dentro de las tradiciones, y suelen ser precisamente quienes están en el centro de cada tradición, confrontados por tradiciones rivales, los que llevan adelante tal proceso. Trasladado a la experiencia del avance del conocimiento humano en general, este esquema presenta una adecuada analogía de cómo tal avance puede ser afirmado con la simultánea afirmación del ideario. En cierto sentido, lo anterior produce un aumento de confesionalidad, un ahondar en el ideario que vuelve explícitas las cosas que una tradición antes llevaba dentro de manera implícita. Se nos vuelve así una vez más patente la manera en que progreso y confesión pueden ir de la mano. Podrá objetarse que esta explicación es sólo una racionalización que esconde las tensiones, que esconde el hecho de que en el proceso de avance del conocimiento lo que con frecuencia se encuentra son cosas que parecen no calzar con la propia visión de mundo. Lo que hemos ofrecido es, efectivamente, una descripción esquemática de un proceso que puede ser lento, tortuoso y cargado de tensiones. Pero en la medida en que la universidad posee un ritmo propio, el ritmo de la búsqueda de la verdad que no está obligada a prestar diarias declaraciones, tales procesos pueden efectivamente tener lugar. 
Que lo anterior sigue dejando abiertas muchas de las objeciones puntuales hechas a las universidades con ideario es evidente. Pero si es aceptado el tipo de posición delineada aquí, tales objeciones pasan de ser objeciones de principio a ser en gran medida objeciones respecto de los criterios prudenciales requeridos para enfrentar escenarios de conflicto. Hemos presentado aquí tres vías de acceso a la discusión sobre las universidades confesionales o con ideario. Contra el argumento puramente fáctico que apunta a su aporte al país (que puede ser valioso, pero que no puede cargar con todo el peso de la prueba), hemos intentado apuntar a tipos de argumentos históricos, políticos y epistemológicos. Tampoco pretendemos que alguno de ellos resuelva por sí solo la discusión, sino que afirmamos la importancia de su fuerza acumulativa. Cada uno de los puntos tocados merece sin duda una atención considerablemente mayor. Pero se trata aquí no de dar por acabada una discusión, sino de abrir rutas promisorias para la misma.

\section{OBRAS CITADAS}

Brading, David. Orbe indiano. De la monarquía católica a la república criolla, 1492-1867. México: Fondo de Cultura Económica, 1991.

Bratt, James. Abraham Kuyper. Modern Calvinist, Christian Democrat. Grand Rapids, MI: Eerdmans, 2013.

Freedman, Joseph. Philosophy and the Arts in Central Europe, 1500-1700: Teaching and Texts at Schools and Universities. Aldershot: Ashgate, 1999.

Gadamer, Hans-Georg. Wahrheit und Methode. Grundzüge einer philosophischen Hermeneutik, 6 $6^{\mathrm{a}}$ ed. Tubinga: J. C. B. Mohr, 1990.

Garrido, Juan Manuel, Hugo Herrera \& Manfred Svensson. La excepción universitaria. Santiago: Ediciones Universidad Diego Portales, 2012.

Gilson, Etienne. Thomist Realism and the Critique of Knowledge. San Francisco: Ignatius Press, 2012.

Jaki, Stanley. Ciencia, fe, cultura. Madrid: Palabra, 1990.

Jaspers, Karl. Balance y perspectiva. Discursos y ensayos. Madrid: Revista de Occidente, 1953.

Kuyper, Abraham. "Soberanía de las esferas". Estudios Evangélicos (junio 2013).

LeGoff, Jacques. Los intelectuales en la Edad Media. Barcelona: Gedisa, 1993.

Lozano Aguilar, José, Pedro Pérez Zafrilla \& Elsa González. "The Limits of Tolerance in Public Universities". Politics in Central Europe 4, n. 2 (2008). 
MacIntyre, Alasdair. Justicia y racionalidad. Conceptos y contextos. Barcelona: Eiunsa, 1994.

Marsden, George. The Soul of the American University. From Protestant Establishment to Established Nonbelief. Oxford: Oxford University Press, 1994. Marsden, George. The Outrageous Idea of Christian Scholarship. Oxford: Oxford University Press, 1998.

Millas, Jorge. Idea y defensa de la universidad. Santiago: Ediciones Universidad Diego Portales, 2012.

Newman, John Henry. The Idea of a University: Defined and Illustrated. Washington: Regnery Publishing, Washington, 1999.

Orellana Benado, Miguel. Pluralismo: una ética del siglo XXI. Santiago: Editorial Universidad de Santiago, 1994.

Putnam, Hillary. The Collapse of the Fact. Value Dichotomy and Other Essays. Cambridge, MA: Harvard University Press, 1992.

Svensson, Manfred. "Hacia una concepción robusta de mera tolerancia". En Una disposición pasajera. Sexto concurso de ensayo en humanidades contemporáneas. Santiago: Ediciones Universidad Diego Portales, 2013.

Tomás de Aquino. In duodecim libros Metaphysicorum Aristotelis expositio. $2^{\mathrm{a}}$ ed. Taurini-Romae: Marietti, 1971.

Weber, Max. Schriften 1894-1922. Editado por Dirk Kaesler. Stuttgart: Alfred Kröner, 2002. EP 